\title{
Patterns of injury associated with automobile airbag use
}

\author{
A A Mohamed, A Banerjee
}

\begin{abstract}
Summary
The wide use of automobile airbags has undoubtedly reduced the mortality and the incidence of serious injuries from motor vehicle accidents. However, automobile airbags appear to be associated with a variety of injuries including fatal injuries, ocular injuries, upper limb and chest injuries. Further improvements in airbag design together with education of the general public in their use should help reduce airbag-related injuries.
\end{abstract}

Keywords: airbags; automobile accidents

Accident and Emergency Department, The Whittington Hospital, Highgate Hill, London N19 5NF, UK

A A Mohamed

A Banerjee

Accepted 23 April 1998
A variety of design modifications have been employed to help reduce morbidity and mortality from motor vehicle accidents. These include lap/shoulder seat belts, head restraints, side-impact protectors, laminated windscreens, and collapsible steering wheel columns. Airbags are a more recent addition to this list. However, they are not completely risk-free and injury can be attributed directly to airbag use. This review looks at the emerging patterns of airbag-related injuries and discusses possible ways of preventing or reducing them. It is necessary for professionals dealing with these injuries to be aware of their mechanisms. The information for this review was retrieved by a Medline search encompassing the years 1991-96, using the keywords 'airbag' and 'injury'. Further references were obtained from the articles generated by this search. Initially 66 references were identified but only 50 were used. Only English language references were utilised. Information was also obtained by direct contact with car manufacturers (Mercedes and Ford) and the Society of Motor Manufacturers and Traders in the UK.

\section{Historical aspects}

Historically, the inflatable restraint system (airbags) used today began as inflatable life jackets used in the second world war. The first automobile airbag patent was issued in $1953 .{ }^{1}$ General Motors provided optional airbags on selected fullsize and luxury car models in the 1970s. Airbags were introduced in the Chevrolet production model of 1973 but the idea was abandoned because of high cost. Chrysler started fitting airbags in its cars in 1974. Airbag effectiveness was optimised in the 1970 s with the development of sodium azide $\left(\mathrm{NaN}_{3}\right)$ solid propellant inflation, which is in use today.

Mercedes-Benz was the first European manufacturer to offer its customers the additional safety feature of airbags in 1981 (Mercedes-Benz, personal communication). However, airbags did not come into common use until the mid-1980s. In the US, Federal Motor Vehicle Standard no 208, Occupant crash protection, stated that fitment of airbags in combination with three-point seat belts would be obligatory from September 1997 for passenger cars and from September 1998 for trucks and vans. ${ }^{2}$ This was probably made necessary by the low compliance with seat belt application in the US. In the UK there is as yet no legislation regarding automobile airbags, despite the fact that they have been proven to significantly reduce morbidity and mortality resulting from frontal collision.

\section{Mechanism of airbag action}

The automobile airbag is a rubber-lined nylon bag which inflates immediately following a frontal collision to form a protective air cushion for the occupant. ${ }^{3}$ The driver-side airbag is housed in the steering wheel while the passenger-side airbag is located in the dash board.

A rapid deceleration of $12 \mathrm{mph} / \mathrm{ms}$ caused by frontal impact or by depression of the front bumper triggers between two to five sensors located in the front bumper of the car. An electrical signal is sent from the sensors which ignites a $70-\mathrm{g}$ solid propellant $\left(\mathrm{NaN}_{3}\right)$ located in a cartridge in the airbag module. Combustion of $\mathrm{NaN}_{3}$ liberates nitrogen gas $(96 \%)$, carbon dioxide and a fine alkaline aerosol comprising sodium hydroxide, sodium bicarbonate and metallic oxides, which are forced under pressure to inflate the airbag in less than $0.05 \mathrm{~s}$ from the moment of impact. ${ }^{4}$ The fully inflated airbag has a volume of 50-60 litres and is propelled out of its compartment at a speed of 100-200 mph in a whip-like fashion. A tethered bag is a variant which has internal straps preventing excessive anteroposterior expansion and allowing more rapid radial expansion. The airbag begins to deflate almost immediately through vents and pores in its lining. This prevents the occupant from bouncing off the inflated airbag. The whole process from impact to deflation only lasts one or two seconds. 


\begin{tabular}{|l|}
\hline Airbag-related injuries \\
\hline - fatal injuries: severe chest injury, head \\
injury \\
ocular injuries: corneal abrasion, \\
chemical keratitis, hyphaema, vitreous \\
haemorrhage, retinal detachment \\
upper limb: abrasion/laceration, \\
fracture/dislocation \\
miscellaneous: chest injuries \\
(abrasions, rib fractures, lung \\
contusion, cardiac trauma); cervical \\
spine fracture; temporomandibular \\
joint dysfunction; barotrauma to the \\
ear
\end{tabular}

Box 1

\section{Patterns of airbag-related injuries}

Automobile airbags have been shown to significantly reduce the morbidity and mortality resulting from frontal collision..$^{5-10}$ However, airbags have also been subsequently implicated as a source of injury to car occupants. These injuries can be divided into four categories (box 1).

\section{FATAL INJURIES}

Although airbags help reduce the morbidity and mortality from vehicle accidents, they may at times contribute to fatality through their deployment. Two cases of airbag-related fatality were first reported in $1993 .{ }^{11}{ }^{12}$ Both fatalities occurred during low-speed crashes while the victims were additionally restrained by three-point lap/shoulder seat belts. The injuries included massive rib fractures with bilateral haemothoraces, fractured sternum, lacerated pericardium and tip of the right auricle with associated haemopericardium, ${ }^{11}$ and left subdural haematoma and cerebral oedema. ${ }^{12}$ Both casualties were of short stature ( 5 feet 2 inches tall) and were only 10 inches from the steering wheel, taking the full force of the expanding airbag. Similarly, an unrestrained 5 feet 2 inches tall driver was killed following a low-velocity motor vehicle collision in which the airbag was deployed. ${ }^{13}$ The severity of injury seemed to be directly related to the proximity of the driver to the rapidly inflating airbag. It is important, therefore, that the driver's seat should be as far away from the steering wheel as possible, with the necessary pedal modification for short people (ie, a higher pedal).

Eight airbag-related deaths of child passengers have been reported. ${ }^{11}$ These were of special concern because they involved low-speed crashes that the children might otherwise have survived. Unrestrained children aged 5 years and 6 years sitting in the front passenger seat were killed when the passenger-side airbag was deployed. ${ }^{14-16}$ They both sustained head injury as a result of contact with the airbag. The importance of restraining the child passenger was strongly emphasised.

A 20-day-old infant seated in a rear-facing child safety seat in the front passenger seat was killed when the passenger-side airbag was deployed. ${ }^{14}$ Rearfacing infant restraints bring the infant in close proximity to the front seat passenger airbag, thus greatly increasing the risk of serious injury or even death. It is vital to make parents aware of this danger and advise them not to fit rear-facing infant restraints in the front seat of a vehicle with a passenger-side airbag. All child safety seats should ideally be placed on the back seat of the vehicle.

\section{OCULAR INJURIES}

These are by far the commonest airbag-related injuries. Since the introduction of airbags as a safety device, many cases of airbag-related ocular injuries have been reported. In one emergency department in the US 14 cases of airbag-related ocular injuries have been identified over a 4-year period. ${ }^{4}$ Most of these were minor self-limiting injuries (nine cases of hyphaema and eight of corneal abrasion). Some of these minor injuries occurred at low speed (10-30 mph) and might not have happened if the airbag had not been deployed. It was thought that, at low speeds, there may be a delay before the sensors transmit the firing signal, making the occupant strike the airbag while it is still expanding. Others have reported moderate to severe ocular injury in relatively low speed crashes in which the airbag was deployed and the occupant was additionally restrained by a three-point lap/shoulder seat belt. ${ }^{17-26}$ These injuries included vitreous haemorrhage and retinal detachment, ${ }^{17}{ }^{18}$ extensive corneal laceration with uveal prolapse, ${ }^{19}$ in which case the severity of the injury was thought to be due to the proximity of the driver's face to the steering wheel (the driver was 5 feet 1 inch tall), and retinal haemorrhage obscuring the macula with resulting reduced vision. ${ }^{20}$ As a general rule, the absence of seat belt application resulted in a more severe ocular injury after airbag deployment. ${ }^{27}{ }^{28}$ In one case, ${ }^{28}$ an unrestrained driver suffered abrasion of eyelids, bilateral lens dislocation and vitreous haemorrhage. His vision remained poor, in spite of operative treatment. It is vital, therefore, to stress the importance of seat belt application in the prevention of serious ocular injury following motor vehicle accidents.

Airbags have indirectly caused ocular injury when objects are projected against the face of the driver. These objects have included eye glasses ${ }^{49}{ }^{30}$ and a tobacco pipe, ${ }^{31}$ which broke causing a penetrating injury to the eye. These injuries occurred at relatively slow speeds and it is of interest to note that the front seat passengers were unharmed. ${ }^{29}{ }^{30}$ It is clear from these cases that objects held between the car occupant and the deployed airbag may be a source of serious ocular injury. It is important to warn the general public of this danger. Activities while driving, such as smoking, drinking, talking on a mobile phone, applying make-up, or reading, should be discouraged. 


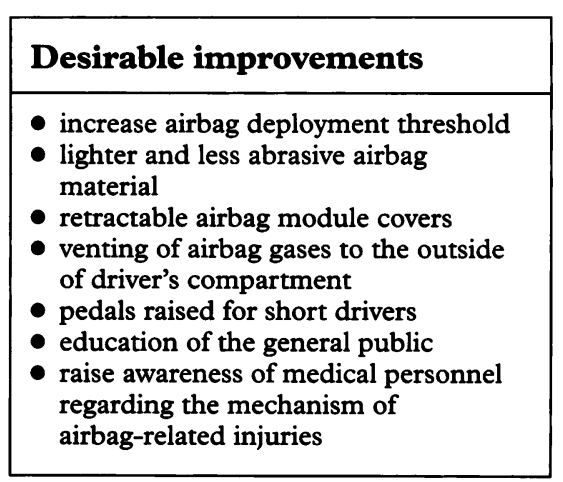

Box 2
Combustion of $\mathrm{NaN}_{3}$ results in the release of sodium hydroxide, sodium bicarbonate and a small amount of unconverted alkali in aerosol form. ${ }^{4}$ These alkaline by-products are released into the drivers compartment on deflation of the airbag. Cases of alkaline chemical keratitis following airbag deployment have been reported. ${ }^{32-35}$ Ocular alkaline burn can cause permanent visual impairment if not diagnosed early and treated promptly. It is therefore imperative that people dealing with these injuries are aware of their mechanism. Early diagnosis by measuring the $\mathrm{pH}$ (normal range 7.0-7.4) of the inferior fornix of the conjunctiva with litmus paper, and prompt treatment by copious irrigation with normal saline are essential for a good prognosis. ${ }^{32}{ }^{33}$

Kuhn $e t a l^{36}$ raised doubts about whether eye injuries (with the exception of alkaline chemical burn) sustained after airbag deployment were actually caused by the airbag or were merely coincidental. They stressed that the implication of airbags as a source of ocular injury should be based on facts and not presumptions. However, continued reporting of airbag-related eye injury is important, as it may lead to recognition of rectifiable problems and improvement in airbag design. It will also help those in the medical, legal and technical fields and the general public to draw informed conclusions.

UPPER LIMB INJURIES

Upper extremity injuries attributable to airbag deployment have been reported. ${ }^{1037-40}$ All the reported injuries occurred in low-speed motor vehicle crashes and varied from minor contusions, abrasions, and lacerations, to severe fractures and dislocations. Swanson-Biearman et $a l^{1}$ reported five cases of chemical burns to hands and fingers or drivers after airbag deployment. This resulted partly from the venting of alkaline aerosol on deflation of the airbag and partly from talc powder. A deployed airbag induced injury by pushing a wrist watch metal strap from the wrist towards the elbow, thereby damaging the superficial veins. The resulting erythema and abrasions mimicked dermatitis artefacta. ${ }^{41}$ A restrained driver and front seat passenger sustained minor burns to forearm and hand, and avulsion fracture of the proximal phalanx of the little finger, respectively, when their airbags were deployed. ${ }^{37}$

The airbag module cover has been implicated in many cases of upper limb injury. ${ }^{38-40}$ Smock and Nichols ${ }^{38}$ reported two cases of upper limb injuries which were a direct result of contact with the airbag module cover. Injuries included avulsion of right thumb and fracture of radius and ulna, with or without elbow dislocation. Both drivers were restrained with lap/shoulder seat belts with their forearm in close proximity with the airbag module cover. Huelke $e t a l^{40}$ analysed 375 motor vehicle crashes in which airbags were deployed. Minor injuries to forearm and hand (abrasion, dislocation, contusion and laceration) occurred in $20-25 \%$ of cases and they were caused by contact with the deployed airbag. They reported nine cases of fracture of radius and ulna, with or without dislocation, as a result of contact with the airbag module cover. Freedman et $a^{\beta 9}$ reported a similar pattern of forearm fractures in two cases, but contact with the airbag rather than the airbag module cover was blamed. Improvement in the airbag module cover design (ie, one which does not project on airbag deployment, eg, a retractable cover) is needed to prevent such injuries.

\section{MISCELLANEOUS INJURIES}

\section{Cervical spine}

Airbags provide specific protection for the cervical spine by allowing a more controlled deceleration of the head. The whiplash motion of the head does not occur because the airbag supports the head and maintains proper alignment of the cervical spine. ${ }^{42}$ However, cervical spine injuries have been directly attributed to airbag deployment. ${ }^{43}{ }^{44}$ Over a period of six months, Blacksin ${ }^{43}$ reported two cases of cervical spine fractures related to airbag deployment. In the unrestrained driver the mechanism of injury was flexion of the upper cervical spine as the driver moved towards the inflated airbag producing end-plate fracture of $\mathrm{C4}$ vertebra with disc herniation. The restrained driver, sitting close to the steering wheel, suffered hyperextension injury resulting in posterior arch fracture of $\mathrm{Cl}$ vertebra.

\section{Chest injuries}

Direct chest contact with the deployed airbag could cause minor injuries such as erythema, abrasions, contusions, and rib fractures of the chest wall. ${ }^{45}{ }^{46}$ However, more serious injuries have been reported. These include sternal fracture ${ }^{43}$; cardiac contusion, pulmonary contusion, and atrial rupture ${ }^{47}$; and aortic valve injury. ${ }^{48} \mathrm{It}$ is important that chest injuries are excluded in all motor vehicle accidents in which the airbag was deployed. 
1 Swanson-Biearman B, Mrvos R, Dean BS Krenzelok ER. Airbags: lifesaving with toxi potential? $\mathrm{Am} \dot{f}$ Emerg Med 1993;11:38-9.

2 Dalmutas DJ, German A, Hendrick BE, Hurly RM. Airbag deployments: the Canadian experience. $\mathcal{F}$ Trauma 1995;38:476-81.

3 Huelke DF, Moore JL, Ostrom M. Airbag injuries and occupant protection. $\mathcal{F}$ Trauma 1992; 33:894-7.

4 Vichnin MC, Jaeger EA, Gault JA, Jeffers JB. Ocular injuries related to airbag inflation. Ocular injuries related to airbag
Ophthalmic Surg Lasers 1995;26:542-8.

5 Zador PL, Ciccone MA. Automobile driver fatalities in frontal impacts: airbags compared with manual belts. Am F Public Health 1993;83: 661-6.

6 King AI, Yang KH. Research in biomechanics of occupant protection. F Trauma 1995;38:570-6.

7 Lund AK, Ferguson SA. Driver fatalities in 1985-1993 cars with airbags. F Trauma 1995; 38:469-75.

8 Antosia RE, Partridge RA, Virk AS. Airbag safety. Ann Emerg Med 1995;25:794-8.

9 Braver ER, Ferguson SA, Greene MA, Lund Braver ER, Ferguson SA, Greene MA, Lund
AK. Reductions in deaths in frontal crashes AK. Reductions in deaths in frontal crashes equipped with passenger airbags. $\mathscr{F} A M A 1997$ 278:1437-9.

10 Huelke DF, Moore JL. Field investigations of the performance of airbag deployments in frontal collisions. Accid Anal Prevent 1993;25:71730 .

11 Jumbelic MI. Fatal injuries in a minor traffic collision. J Forensic Sci 1995;40:492-4.

12 Smock WS, Nichols GRD. Airbag induced fatal injuries: a case report. Presented at the 45th injuries: a case report. Presented at the 45th annual meeting of the American Academy of

13 Brown DK, Roe EJ, Henry TE. A fatality associated with the deployment of an automobile airbag. F Trauma 1995;39:1204-6.

14 Centres for Disease Control and Prevention. Airbag associated fatal injuries to infants and children riding in the front passenger seat United States. $¥ A M A$ 1995;274:1752-3.

15 Bourke GJ. Airbags and fatal injuries to children. Lancet 1996;347:560.

16 Anon. Air-bag-associated fatal injuries to infants and children riding in front passenger seats -United States. $M M W R$ 1995;44:845-7.

\section{Other injuries}

Direct impact of the mandible or ear on the deployed airbag could cause bilateral temporomandibular joint injury ${ }^{49}$ and barotrauma of the ear, ${ }^{50}$ respectively.

17 Han DP. Retinal detachment caused by airbag injury. Arch Ophthalmol 1993;111:1317-8.

18 Whitacre MM, Pilchard WA. Airbag injury producing retinal dialysis and detachment (letter) Arch Ophthalmol 1993;111:1320.

19 Baker RS, Flowers CW Jr, Singh P, Smith A, Casey R. Corneoscleral laceration caused by airbag trauma. Am $\mathcal{f}$ Ophthalmol 1996;121:70911.

20 Sastry SM, Copeland RA, Mezghebe H, Siram SM. Retinal haemorrhage secondary to airbagrelated ocular trauma. F Trauma 1995;38:582.

21 Campbell JK. Automobile airbag eye injuries. Nebraska Med $\mathcal{f}$ 1993;306-7.

22 Michaeli-Cohen A, Neufeld M, Lazar M, Geyer O, Haddad R, Kashtan H. Bilateral corneal $\mathrm{O}$, Haddad $\mathrm{R}$, Kashtan $\mathrm{H}$. Bilateral corneal bag (letter). Br $\mathcal{F}$ Ophthalmol 1996;80:487.

23 Lesher MP, Durrie DS, Stiles MC. Corneal oedema, hyphaema and angle recession after airbag inflation (letter). Arch Ophthalmol 1993; 111:1320-2.

24 Rimmer S, Schuler JD. Severe ocular trauma from a driver's side airbag. Arch Ophthalmol 1991;109:774.

25 Larkin GL. Airbag-mediated corneal injury. $\mathrm{Am}$ f Emerg Med 1991;9:444.

26 Mishler KE. Hyphaema caused by airbag. Arch Ophthalmol 1991;109:1635.

27 Rosenblatt MA, Freilich B, Kirsch D. Airbag associated ocular injury (letter). Arch Ophthalmol 1993;111:1318.

28 Onwuzuruigbo CJ, Fulda GJ, Larned D, Hailstone D. Traumatic blindness after airbag stone $\mathrm{D}$. Traumatic blindness after airbag
deployment: bilateral lenticular dislocation. $\mathcal{F}$ deployment: bilateral lent

29 Gault JA, Vichnin MC, Jaeger EA, Jeffers JB. Ocular injuries associated with eyeglass wear and airbag inflation. $\mathcal{F}$ Trauma 1995;38:494-7.

30 Molia LM, Stroh E. Airbag injury during low impact collision. Br $\mathcal{F}$ Ophthalmol 1996;80:487.

31 Walz FH, Mackay M, Gloor B. Airbag deployment and eye perforation by a tobacco pipe. $f$ Trauma 1995;38:498-500.

32 Smally AJ, Binzer A, Dolin S, Viano D. Alkaline chemical keratitis: eye injury from airbags. $A n n$ Emerg Med 1992;21:1400-2.

33 White JE, McClafferty $\mathrm{K}$, Orton RB, Tokarewicz AC, Nowak ES. Ocular alkali burn associated with automobile air-bag activation. Can Med Assoc $\mathcal{F}$ 1995;153:933-4.
34 Weinman SA. Automobile airbag-mediated injury: a case presentation. $\mathcal{f}$ Emerg Nur 1995;21:84-5.

35 Ingraham HJ, Perry HO, Donnefeld ED. Airbag keratitis (letter). N Engl f Med 1991;324:1599600.

36 Kuhn F, Morris R, Witherspoon CD, Byrne JB, Brown S. Airbag: friend or foe? Arch Ophthalmol 1993;111:1333-4.

37 Roth T, Meredith P. Hand injuries from inflation of an airbag security system. $\mathcal{f}$ Hand Surg 1993;18B:520-2.

38 Smock WS, Nichols GR II. Airbag module cover injuries. F Trauma 1995;38:489-93.

39 Freedman EL, Safran MR, Meals RA. Automotive airbag-related upper extremity injuries: a report of three cases. $\mathcal{F}$ Trauma 1995;38:577-80.

40 Huelke DF, Moore JL, Compton TW, Samuels J, Levine RS. Upper extremity injuries related to airbag deployments. $\mathcal{F}$ Trauma 1995;38:482-8.

41 Burton JL. Air-bag injury (letter). $\mathcal{f}$ Accid Emerg Med 1994;11:60.

42 Jagger J, Vernberg K, Jane JA. Airbags:reducing the toll of brain trauma. Neurosurgery 1987;20: 815-7.

43 Blacksin MF. Patterns of fractures after airbag deployment. F Trauma 1995;35:840-3.

44 Traynelis VC, Gold M. Cervical spine injury in an air bag equipped vehicle. $\mathcal{f}$ Spinal Disord 1993;6:60-1.

45 Zipperman HH, Cromack JR, Clark TM. Airbags and seat belts in injury amelioration. $\mathcal{F}$ Trauma 1976;16:686-93.

46 Beckerman B, Sama A. Airbag "tattoo", a lasting impression. F Emerg Med 1995;13:683-5.

47 Lancaster GI, DeFrance JH, Borruso JJ. Airbag associated rupture of the right atrium (letter). $N$ Engl F Med 1993;328:358.

48 Reiland-Smith J, Weintraub RM, Selke FW. Traumatic aortic valve injury sustained despite the deployment of an automobile airbag. Chest 1993;103:1603.

49 Garcia Jr R. Airbag implicated in temporomandibular joint injury. $\mathcal{f}$ Craniomandibular Pract 1994;12:125-7.

50 Beckerman B, Elberger S. Airbag ear (letter). Ann Emerg Med 1991;20:831-2. 